\title{
Meeting Diverse Information Needs
}

\section{Students with Disabilities}

\author{
Jan Murray \\ <murryan@gsat.edu.au>

\section{Doctoral Candidate, School of Information Management and Systems Monash University, Melbourne Australia.}

This paper presents the results of a four-year study conducted in primary and secondary schools from all sectors in two Australian states, Victoria and New South Wales. The study investigated the impact of inclusive schooling on the provision of library and information services to students with disabilities. The methodology used in the study incorporated both survey and case study. Empirical data collected by survey concentrated particularly on the current level of service provision to students with disabilities, whilst case study investigations also looked at management factors. The focus was on the relationship between the school library staff and the special education staff, and the effect this had on school library provision and the acquisition of information skills by students with disabilities. The discussion includes the level of service provision to students with disabilities, as well as the managerial approach of teacher-librarians and their awareness of appropriate resources, teaching approaches and technology.

\section{Introduction}

Educational legislation and policy has promoted for sometime the inclusion of students with disabilities in mainstream school. Most schools have some students with disabilities and usually follow one of two models: either there is a special education team providing support to students with disabilities in the mainstream, or there is a separate unit or support classes attached to the school catering to children with one or more specific disabilities. Although there are several prescriptive texts on school library services to students with disabilities (Walling \& Karrenbrock, 1993; Wesson \& Keefe, 1995; Marshall, 1991), little evaluation has been carried out. The only recent piece of evaluative research appears to be the British Library funded Learning Support for Special Educational Needs (LESSEN) project (Heeks \& Kinnell, 1997) which investigated the role of learning support for Year 7 pupils with learning difficulties in ten United Kingdom secondary schools and was in progress at the same time as the current study. The project identified ways in which school libraries could contribute to the education of students with special needs; these included creating a welcoming library environment; development of library policy that is linked to school policy; and knowledge by professional library staff of both students with special needs and appropriate resources for them. 


\section{Definitions}

The study took as its reference the Federal disability legislation, and disability was used as it is defined in that legislation. The Disability Services Act 1986 (DSA) was the first piece of disability legislation in Australia. It recommended that services such as education, transport, and accommodation for people with disabilities should be mainstreamed. The DSA covers people with intellectual, psychiatric, sensory, or physical impairments. The Disability Discrimination Act 1992 (DDA) makes it illegal to discriminate against any person because of a disability. The DDA extends the DSA definition to include learning disability. These definitions could a very wide range of school students.

\section{The Focus of the Research}

Research questions were identified to direct data collection that would demonstrate the success or failure of school library managers to meet the legislative requirements of disability legislation. Empirical data collected by survey would concentrate on the current level of service provision to students with disabilities, whilst case study investigations would also look at management factors. Awareness of the need for an inclusive curriculum could be investigated by finding out how information skills are being taught to students with disabilities. Development of policy documents that ensure acceptable standards of school library service to students with disabilities would indicate an awareness of legislative requirements as well as good management practice in creating such documents. Additional funding of school libraries to enable the legislative requirements for service provision to be met would be a similar indicator. Public, state, and voluntary agency libraries play an important supportive role to school libraries, and the extent of this support and knowledge of such services by school librarians were important issues. Knowledge of disability legislation, and the source from which the knowledge was acquired, would indicate the level to which government had been effective in disseminating information about mandatory requirements.

\section{Methodology}

Methodological triangulation was achieved by using multiple case studies and document analysis alongside a longitudinal survey approach. Exploratory interviews were conducted in some case study schools prior to the design of the survey instrument so that data collected might assist in the questionnaire design. A second survey was administered almost two years later to measure changes in provision and knowledge and attitudes towards the research questions. Documents analyzed included federal and state legislation and policy documents, school policy documents, and professional standards that had relevance to the research questions.

\section{The Surveys}

The survey instrument was a self-administered questionnaire, which was designed to collect mainly quantitative data but also included some open questions. A sheet defining the disabilities being covered was attached to the questionnaires. The first questionnaire was sent 
to the principals of 1500 schools, 750 in Victoria and 750 in New South Wales (NSW). A computer generated stratified random sample ensured distribution across all school sectors and levels equivalent to the proportion of schools in each sector. An accompanying letter requested that the questionnaire be completed by the staff member responsible for managing the library or resource centre in the school.

The second survey was distributed in June 1996 to all 492 respondents to the first survey. The questionnaire was amended slightly and piloted beforehand by the same school librarians who had piloted the first questionnaire. Three questions about staff development, funding, and physical access were amended to ask if anything was different since 1994. One question was added about legislation that had the most effect on school library services to students with disabilities.

There were 492 (33\%) valid responses to the first survey: 285 from Victoria and 206 from NSW. Representation across sectors from the two states compared favourably with the national statistics: there are 72\% government schools, 19\% Catholic schools, and 9\% independent schools (Lemos, 1994); the sample was 72\% Government schools, $25 \%$ Catholic schools, 3\% Independent schools. The follow-up questionnaire was distributed to the 492 respondents to the first questionnaire, and achieved a response rate of 53.5\% (264). School sector representation again compared well with the national average (77\% Government schools, 19\% Catholic schools and 3.4\% independent schools).

SPSS- $X$ was used for all quantitative data analysis of fixed response questions. This consisted mainly of frequency distributions and cross-tabulations. Where chi-square tests were used, results were regarded as statistically significant if the level of significance or probability was less than 0.1 or more than 0.5 .

\section{The Case Studies}

Case study schools were selected through personal contacts and professional networks and met the following criteria: a qualified librarian or teacher-librarian managed the school library; and, teaching staff within the school administered the special education program. All educational sectors at both primary and secondary levels were represented. Fourteen case study schools were selected from a range of socio-economic areas within the metropolitan districts of Sydney and Melbourne. There was also an opportunity to visit three schools in British Columbia, Canada and two schools in Nottinghamshire, United Kingdom. Both of these education authorities had established reputations in both school library provision and special education; thus additional data were collected to offer some point of international comparison.

Each Australian school was visited several times during the four years of the study. Data triangulation was achieved by interviewing a range of people in each school: library staff (teacher-librarians, librarians, library technicians, clerical assistants), special education staff (teachers and aides), and students with disabilities. Interviews were not structured beyond the use of interview guides. This open-ended approach allowed any avenue to be explored within the interview. The literature review indicated that research into special education had rarely 
involved interviewing students, and this was perceived to be a future research need (Wade \& Moore, 1993). Thus the present study could contribute to this gap in research to some extent.

The focus was on the relationship between the school library staff and the special education staff, and the effect this had on school library provision and the acquisition of information skills by students with disabilities. Clearly there would be a considerable range in facilities, staffing, and funding between the case study schools. Thus the decision was made to work in less depth with a number of schools, rather than intensively with one or two schools. In this way the data collected might indicate which model of special education best facilitated effective use of the school library and the teaching of information skills. The managerial and communication skills of the school librarian would be an important factor determining the level of library service provided within a school; therefore it was desirable to observe and record the skills of school librarians operating in different school environments. These requirements favoured the adoption of the constant comparative case study method that was initially developed in the work of Glaser and Strauss (1967).

\section{Results}

\section{The Surveys}

Of the schools in the study, $92(18 \%)$ had no students with disabilities; 209 schools (42\%) had between 1-5 students with disabilities; 88 schools (18\%) had 11-15 students with disabilities; and 83 schools identified 16 or more.

The results of a cross- tabulation for students with disabilities by school sector is shown in Table 1 below.

\section{Table 1. Students with Disabilities by School Sector}

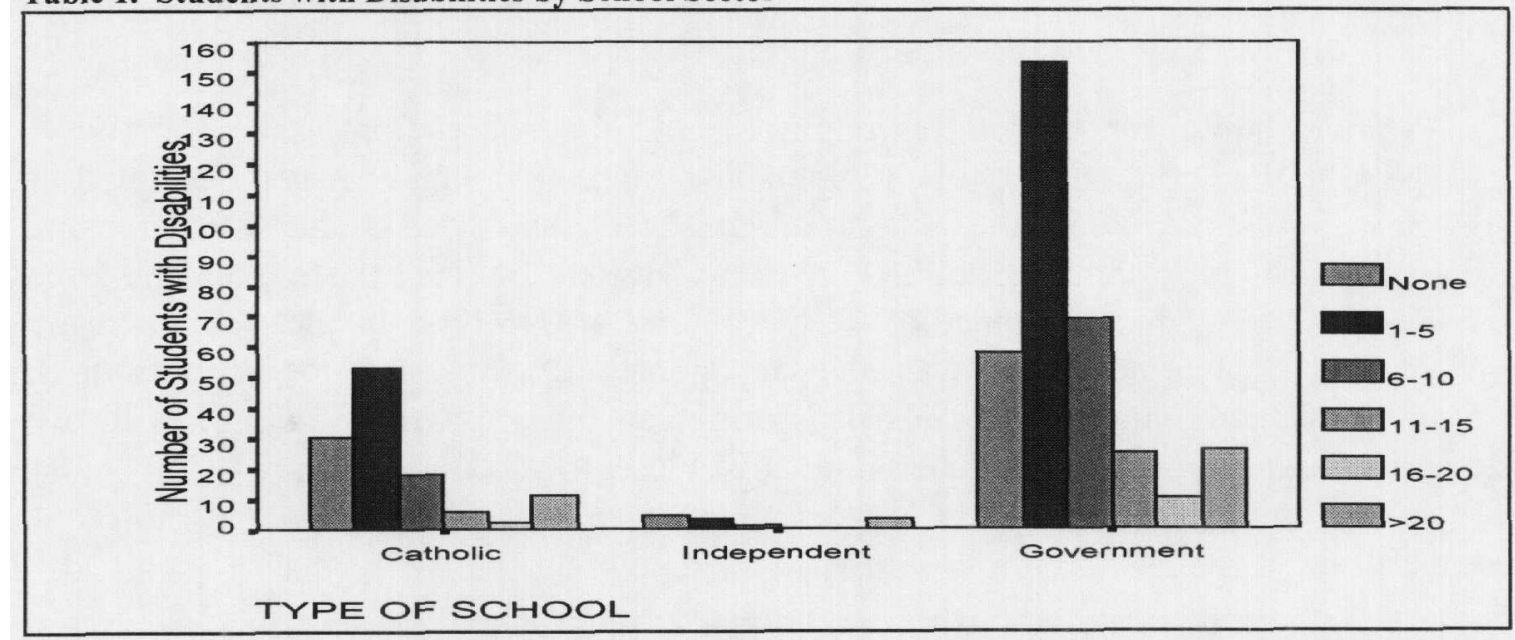

The highest number of students with disabilities were enrolled in government schools, the majority of which had between one and five students. In 1996, school librarians reported higher numbers of students with disabilities, especially in the higher grade ranges. So, whereas in $1994,6 \%$ of schools reported 11-15 students with disabilities enrolled, in 1996 it was $9 \%$. In 1994, 2.4\% of schools reported 16-20 students with disabilities enrolled; in 1996 
this had risen to $4.5 \%$. In $1994,4 \%$ of schools reported that there were no students with disabilities enrolled; in 1996 only one school (.4\%) reported no enrollments.

Staff development programs relevant to serving students with disabilities were available in $52 \%$ of the schools which had students with disabilities enrolled. special staff meetings, inhouse staff development activities, or talks by external experts were some of the programs mentioned by the questionnaire respondents.

Only 15 schools $(3 \%)$ had allocated extra funding to purchase resources for students with disabilities. Qualitative comments indicated that in several cases the special education department had purchased material to be housed in the school library. A few respondents indicated that they had received funding for specialized resources or equipment.

The library was easily accessible for students with disabilities in 301 (61\%) schools. Problems with accessibility were frequent because libraries were not on the ground floor or access involved negotiating steps. Respondents' comments also pointed out that some school library staff members were aware of less obvious barriers to physical access such as insufficient space between shelves for wheelchairs and high and low shelves that are inaccessible to wheelchair users. Thirty-six libraries $(13.7 \%)$ improved physical access between 1994 and 1996.

Many of the school libraries in the study (141 or $28.7 \%$ ) did not offer any special facilities for students with disabilities. Of those that did, the services most frequently provided were personal help, flexible borrowing, and clear signage. Table 2 below shows the pattern of provision.

Table 2. Provision of Special Facilities in 1994

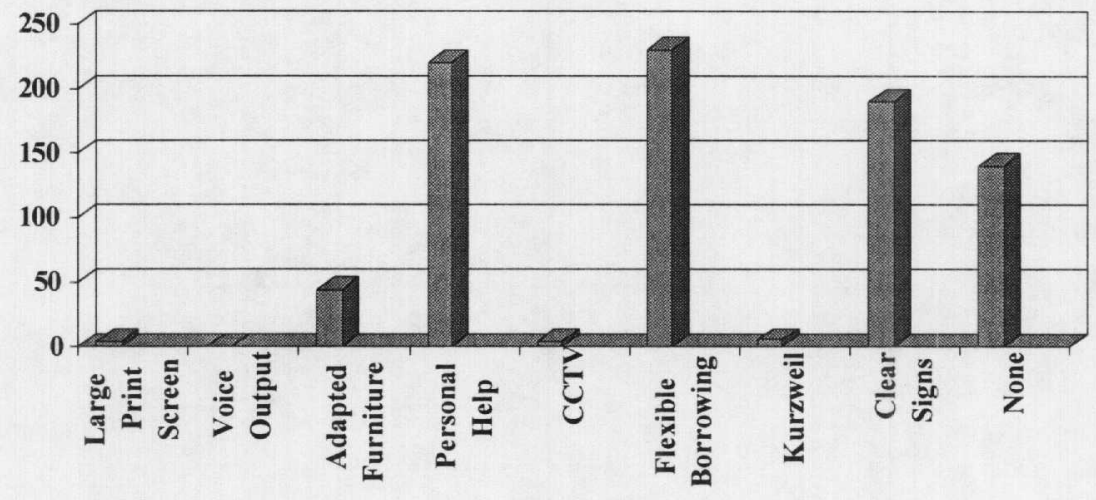

In 1996, more libraries were providing large print screens for the catalogue, adapted height furniture, and flexible borrowing.

The questionnaire asked if libraries stocked large print books, audio books and magazines, subtitled videos, and books with high interest but low vocabulary level (generally referred to as hi/lo books). Thirty-five libraries (7\%) did not stock any of these materials; $72 \%$ stocked hi/lo books; $54 \%$ had audio books; $27 \%$ had large print books; $3.7 \%$ stocked videos with subtitles; and 3.3\% had audio magazines. 
In 1996 fewer libraries reported stocking large print books and other alternative format materials. Two hundred and forty-two respondents (49\%) stated that they knew where to obtain specialized or transcribed materials for students with disabilities; sources cited were local public libraries, state libraries or agency libraries.

Qualitative comments collected as part of the survey data indicated a range of approaches to the teaching of information skills to students with disabilities. Some school librarians included such students as part of the main class; others organized one-to-one instruction by either library staff, a special education teacher, or an aide, whilst other children were taught by a librarian. Other respondents indicated they used a wide range of teaching strategies in dealing with these students and were very aware of their specific needs, often modifying worksheets and other teaching materials as necessary. Some reported that there was insufficient staffing and time to cater for any extra needs.

The questionnaire asked whether the school had a formal policy on integration (this term was used as it was the terminology currently in use in both states) and also whether the school library itself had a policy statement about services to students with disabilities. In 57 schools (11\%) the library manager did not know whether the school had a formal policy. In 1994 only 23 school libraries $(4.7 \%)$ had a formal policy regarding services to students with disabilities, and in 1996 only eight libraries (3\%) had such a policy.

Respondents were asked to indicate their awareness of disability legislation on a scale of one to five. Table 3 below shows the results.

Table 3. Awareness of Disability Legislation in 1994

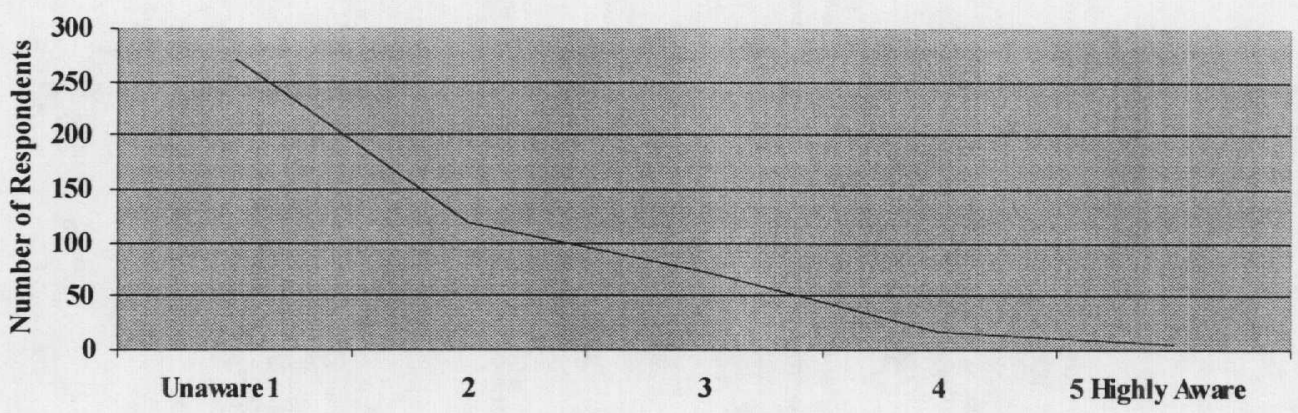


Those respondents who were aware of the legislation, were asked how they found out about it. Table 4 shows the results.

Table 4. Sources of Information about Disability Legislation

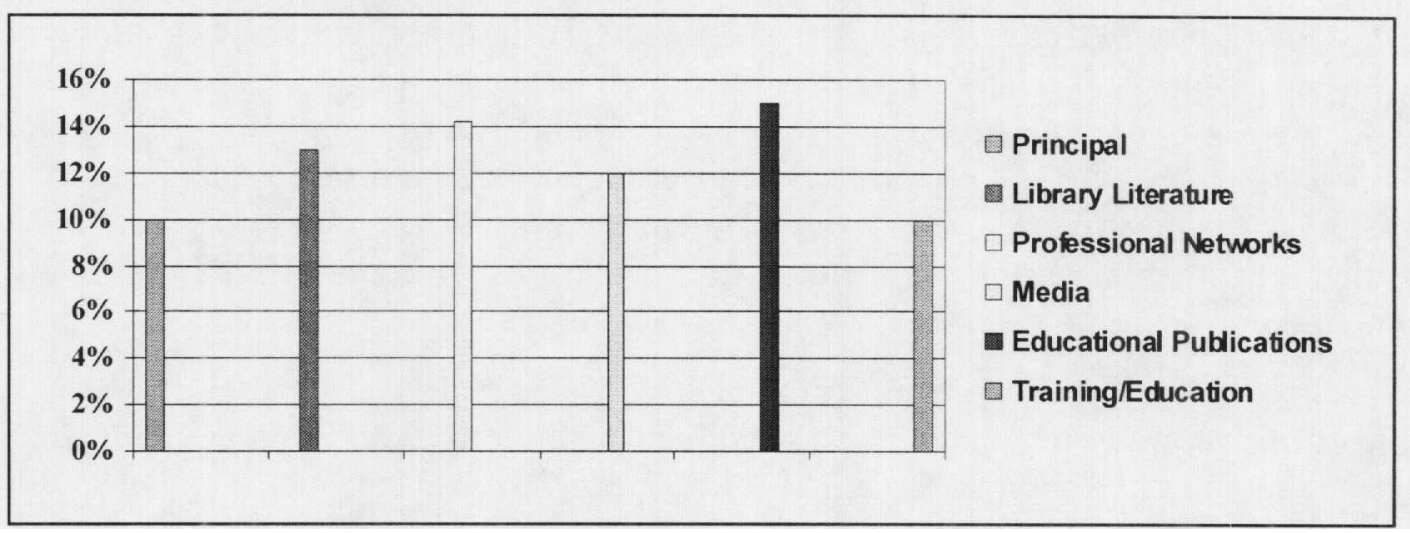

There was very even distribution across the various sources, the highest sources of information about disability legislation being professional networks (14.2\%) and educational publications (15\%). This same group of respondents was asked to comment on the extent to which the DDA had affected their library practice, and the results are shown in Table 5 below.

Table 5. The DDA and School Library Practice

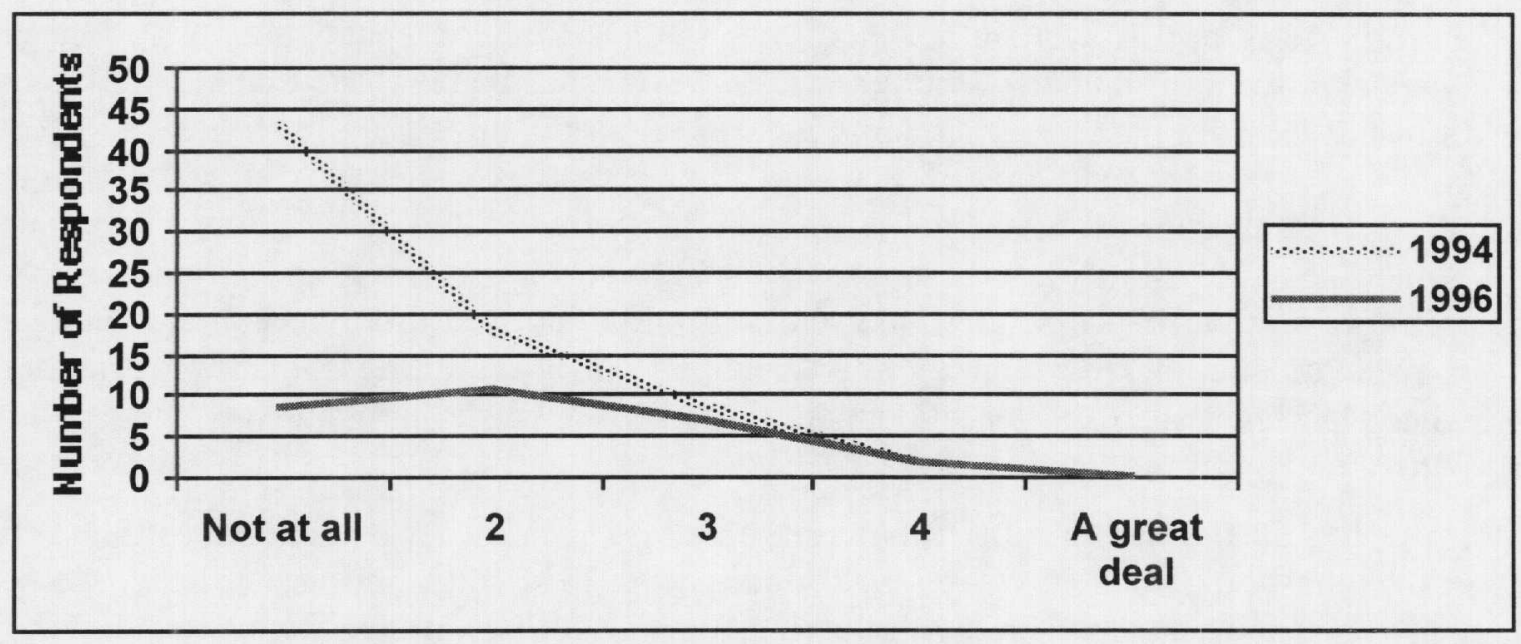

\section{The Case Studies}

There did not seem to be any overt connection between the special education model used in the school and the overall effective use of the library by students with disabilities. In some schools with a special education support unit, there was a distancing of the students from the rest of the school population, especially when the support unit was physically remote from the main school buildings. In these schools special education teachers might be reluctant to go to the library with their students because it took up too much time. In some schools, the 
"ownership" of students with disabilities was an issue for special education staff: in these cases special education teachers did not give school librarians the opportunity to teach information skills to these students, or felt it was not a high priority.

Only two school libraries covered services to students with disabilities in policy documents. However, most school librarians emphasized that their services were attuned to the individual needs of every student. Awareness of disability legislation was very low; most school librarians were aware of equal opportunity legislation but not the disability legislation. They were aware that there was a legal requirement to provide services for students with disabilities, but they were not cognizant of the legal consequences of non-compliance or discrimination.

Several school library staff working in the case study schools had personal experience of disability from a variety of experiences: teaching, community work, or the involvement of family members in the disability field. This did appear to be a factor in the understanding of the needs of students with disabilities, especially if library staff had not had the opportunity to attend staff development activities related to service provision for people with disabilities. Special education staff in nearly all the case study schools did provide staff development activities of some kind for the teaching staff, but these either did not include clerical staff or were held outside of school hours and clerical staff were not willing to stay to attend on their own time.

Many school libraries still have entrance doors that are heavy and difficult to handle so that wheelchair users are forced to use entrances different from those used by other students. Some libraries provided less obvious features of good physical access such as providing an enquiry terminal at wheelchair height, and is sufficient space between shelving for wheelchairs. Unfortunately, most libraries are so restricted by space that all shelves have to be used with the result that students in wheelchairs have to rely on library staff or other students to access material for them on higher or lower shelves. Several students with physical disabilities expressed great frustration at being limited in their browsing in this way. Sometimes accessibility can be improved at little cost by rearranging shelving or providing furniture at a particular height. One school librarian noticed that when she had temporarily moved an enquiry terminal to a low table whilst upgrading the system, students in wheelchairs and also shorter students preferred using it: she now has one enquiry terminal permanently at that level.

Provision of alternative format materials in school libraries was mainly restricted to hi/lo books and book/tape kits. Captioned videos were held in the libraries of the two schools which had units for students with hearing impairment but in no others. Very few libraries stocked large print books, even when there were students with vision disabilities enrolled in the school. The only case study school that had many large print books in its collection was Nottinghamshire, United Kingdom which had 16 students with visual impairment. Initially all students at the school were allowed to borrow large print books, but due to demand, borrowing was eventually restricted to the students with visual impairment. This indicates that large print books may be a more useful resource than school librarians realize. Several school librarians found that their collection of mature age picture books were a useful resource for students with intellectual or learning disabilities. Such books were a worthwhile resource investment as they could be used in other curriculum areas such as art and design. In 
some schools the special education department had placed a collection of easy reading material in the library for the use of students with intellectual or learning disabilities. However, several school librarians did not favor "separate "collections as the students using them tended to be stigmatized. As an alternative, easier reading materials were interfiled with the rest of the collection, but were tagged in the catalogue so that they could be readily identified.

The involvement of special education staff in the selection of resources was not always evident. In some schools there had been no initiative by either library or special education staff. In others there was constant involvement in selection by the school librarian and the special education teacher as a team. Few special education teachers, however, considered using the school librarian as a source of advice for selection of classroom resources. Dissemination of information about resources to special education staff from the library seemed to be limited to directing appropriate publishers' fliers and catalogs, or publicizing bookseller visits to the school. Special education teachers located the resources they required through publishers' catalogues or by browsing through displays at conferences. They also consulted with specialists visiting the school or other professional colleagues. Many had identified and worked with booksellers who specialized in the type of materials they needed.

Although school librarians are experienced users of information technology, there was no evidence of the recognition of the role of technology in compensating for disabilities. Adaptive technology can provide many options such as access to print for visually impaired students and keyboard use for students with little motor control. Several school librarians had realized the benefits of electronic information sources for many students, especially those with intellectual disabilities or learning difficulties. These related to the relative ease of searching some electronic information products compared to their more traditional print counterparts.

Most of the school libraries assessed offered extra services, such as extended loan periods, and made staff available to assist students with physical disabilities in retrieving items from the shelves. Some school library staff would enlarge materials by photocopying, but often the adaptation of materials was the responsibility of the special education staff.

Very few schools cooperated closely with their local public library, except for a specific information need. One school library borrowed large print material from the local public library from time to time for a student with visual impairment. In one case study school, the school librarian exchanged for a year with a Canadian librarian. The Canadian librarian had worked very closely with the local public library in his home situation, and on arrival at the Australian school, he automatically used the public library when needed. To him, it was the obvious thing to do.

There were a variety of scenarios for teaching information skills to students with disabilities. Some students participated in library activities with their normal class; others visited the library in small groups with their special education teacher; and some visited the library on an individual basis with their aide. Students with sensory disabilities, intellectual disabilities, or learning disabilities usually needed some modifications in information skills instruction. In some cases the aide would work with the student in the library lesson, modifying material as necessary. Frequently the school librarian would adapt worksheets and other material to suit an individual student's needs, or modify the expectations for individual students. This latter 
option ensured the inclusion of a student with a disability, as he or she would be doing the same work as the other students, but with either modified outcomes or a different tool. The most successful situations were those where the school librarian had consulted closely with the special education teacher as to the content of information skills programs. Aides did not always accompany students to the library. In some cases this gave the opportunity for the student to exercise some independence, but in others it was detrimental to the information skills teaching process. If a student needed one-on-one attention, the librarian could not effectively assist while dealing with the class as a whole. If one of the chief roles of the aide was to keep the student on task or modify materials, it was crucial for the aide to accompany the student to the library.

\section{Conclusion}

The results of this study show that the inclusion of students with disabilities in mainstream schools is increasing. School librarians cannot ignore the needs of this client group, and they certainly need to develop a library policy that reflects the school policy on inclusion. They must also be aware disability legislation when planning library services. However, successful delivery of services is dependent on appropriate support, both practical and financial, for resources and teaching programs.

The researcher's previous experience indicated that disability awareness training was essential for library staff, especially in a school environment. The case study and survey responses indicated that current school staff development programs were not meeting the needs of library staff. Professional associations and education department training units might consider offering specific programs for library staff from a group of schools.

School libraries with limited funding are not able to purchase a vast range of alternative format materials, some of which can be expensive. School library managers need to be more assertive in ensuring that some of the funding provided to support students with disabilities is apportioned to the library. Otherwise resources have to be obtained from outside of the school on a temporary basis; often there can be a delay in obtaining such materials, and many library staff were not aware of where such resources were available.

The incidence of facilities and services available for students with disabilities in school libraries was also of concern. If these factors were considered in collection development and service planning as a matter of course, then individual libraries would be better equipped to deal with the differing needs of students with disabilities who might enrol in the school. For students with disabilities, apart from access issues, the effective use of technology can improve academic performance, classroom behaviour, motivation and self-concept. (Lewis, cited Male, 1997).

Both surveys showed that good physical access existed in a reasonable proportion of school libraries, a result to be expected as access is the primary issue addressed by most organizations in complying with the legislation. Even so, everal case study schools had libraries with significant problems regarding physical access. School librarians must be aware of legislative requirements for physical access, especially when planning new library buildings. 
The qualitative data collected about information skills teaching indicated that school librarians were aware that students with disabilities had specific needs in this area, but as inclusive schooling becomes more established, teaching strategies in this area will need more attention.

The results of the study indicate that there is considerable room for improvement in the provision of school library services to students with disabilities. School library managers must have knowledge of students with disabilities in the school, provide appropriate resources for them, and develop library policy that is linked to school policy.

The case study data indicated that the following key factors are critical in effective delivery of library services to students with disabilities: well established two way communication between the library staff and the special education staff; size of the school; personal experience of disability or disability awareness training on the part of the library staff; involvement of special education staff in the selection of library resources; involvement of special education staff in the information skills program; and the support of aides where necessary. In addition, information gathered from case study schools made it clear that the culture of the school affects the amount of interaction between the school library and the special education department. Apart from this, the personalities and managerial approach of the school librarian and the head of the special education department were crucial to success. Where the school librarian was a good manager, the resulting level of service meant that students with disabilities were supported, within funding restraints. Observations and data collected from schools in the UK and Canada indicate that these issues and challenges have universal application for school librarians. 


\section{References}

Alliance for Technology Access. (1994). Computer resources for people with disabilities. Alameda, CA: Hunter House.

Disability Services Act. 1986. Canberra: Australian Government Publishing Service.

Disability Discrimination Act, 1992. Canberra: Australian Government Publishing Service.

Glaser, Barney G., \& Strauss, Anselm L. (1967) The discovery of grounded theory : Strategies for qualitative research. Chicago: Aldine.

Heeks, Peggy \& Kinnell, Margaret.(1997). Learning support for all? Special needs pupils and learning resources. Journal of Librarianship and Information Science, 29 (3), 143153.

Lemos, Molly de. (1994). Schooling for students with disabilities. Canberra: ACER/DEETYA

Lewis, R. (1993). Special education technology: Classroom applications. Pacific Grove, CA: Brooks/Cole; cited by Male, Mary. (1997) Technology for inclusion: Meeting the special needs of all students. Boston, MA: Allyn \& Bacon.

Marshall, Margaret. (1991). Managing library provision for handicapped children. London: Mansell.

SPSS Base 8.0 for Windows User's Guide. (1997). Chicago: SPSS Inc.

Wade, Barrie, \& Moore, Maggie. (1993). Experiencing special education. Buckingham: Open University Press.

Walling, Linda Lucas, \& Karrenbrock, Marilyn H. (1993). Disabilities, children and libraries: Mainstreaming services in public libraries and school library media centers. Englewood, CO: Libraries Unlimited.

Wesson, Caren L., \& Keefe, Margaret J. (Ed.). (1995). Serving special needs students in the school library media center. Westport, CN: Greenwood Press. 